\title{
EDITORIAL \\ LA GARANTÍA JUVENIL REFORZADA COMO VÍA CARDINAL PARA EL EMPLEO DE LOS JÓVENES.
}

\author{
Ferran Camas Roda \\ Catedrático de Derecho del Trabajo y de la Seguridad Social y Director de la Cátedra de \\ Inmigración, Derechos y Ciudadanía de la Universitat de Girona.
}

El año 2021 ha empezado jurídicamente hablando en materia laboral con la aprobación del Real Decreto-ley 2/2021, de 26 de enero, de refuerzo y consolidación de medidas sociales en defensa del empleo, conocido sobre todo por prorrogar la aplicación de diversas modalidades de expedientes de regulación temporal de empleo iniciados al amparo de la normativa de emergencia adoptada con motivo de la pandemia de la Covid19 , pero que también incorpora modificaciones de interés respecto al sistema nacional de garantía juvenil, que fue creado por la Ley 18/2014, de 15 de octubre, de aprobación de medidas urgentes para el crecimiento, la competitividad y la eficiencia. Esta norma supuso la culminación en España de las recomendaciones de la Unión Europea para implantar una garantía juvenil en todos sus Estados miembros con el objetivo básico de velar que los jóvenes recibiesen una oferta de empleo o de formación en un periodo de cuatro meses tras quedar desempleados o abandonar la educación formal.

A ese fin se aboca el sistema nacional de garantía juvenil a través de la implicación activa de diversos organismos, desde las administraciones públicas (estatales, autonómicas y locales) hasta los agentes sociales, pasando por las entidades del sector privado (ONGs, entidades sociales, etc.), para que proveyesen de empleo o formación a la juventud, desarrollasen acciones de intermediación y fomento del empleo, e hiciesen un seguimiento de todos los programas que se activasen. Especial relevancia tuvo, y sigue teniendo, la creación del fichero del sistema como soporte de información sobre la garantía juvenil, cuya plena potencialidad debe exigirse, no solo para evitar disfuncionalidades entre territorios, sino para conocer y difundir plenamente los resultados de la garantía juvenil.

En todo caso, los beneficiarios de la garantía juvenil han sido desde el principio los jóvenes, si bien lo que debe entenderse por dicha franja vital a los efectos del sistema ha ido evolucionando progresivamente desde la Ley 18/2014, para acabar comprendiendo a todas las personas de 16 a menos de 30 años (regulación establecida en 2019). La condición para recibir una oferta de empleo o una acción de formación ha venido siendo que dichos jóvenes no estén ocupados ni integrados en los sistemas de educación o formación, colectivo que se ha venido conociendo como "nini", si bien hay que recordar 
que esta calificación no equivale a que la persona joven en cuestión nunca haya estudiado ni trabajado, sino que en el momento de acceder al sistema de garantía juvenil no esté haciendo ni una cosa ni otra. Además, otra característica del sistema nacional de garantía juvenil que también ha sido objeto de cambios desde la adopción de la Ley 18/2014 ha sido la distancia entre la realización de un curso o de un empleo por un joven y la entrada en el sistema, regulación que al principio era verdaderamente exigente en el sentido de autorizar únicamente el acceso a jóvenes que hubiesen llevado a cabo aquellas acciones con un mes de antelación a la fecha de entrada en el sistema, hasta lo que se pide actualmente, tributario de la modificación legal llevada a cabo en el 2016 con el objeto de impulsar la garantía juvenil, que es únicamente no haberse formado ni haber estado empleado justo el día anterior a solicitud de acceso (reforma legal que se arbitró a través Real Decreto-ley 6/2016, de 23 de diciembre de medidas urgentes para el impulso del Sistema Nacional de Garantía Juvenil).

Finalmente, como último requisito de importancia para poder beneficiarse de las acciones del sistema de garantía juvenil, se venía imponiendo que el joven tuviera un interés activo en acceder a él a través de su inscripción en el registro que se creaba al efecto e hiciera una declaración expresa de interés de participar de las acciones de garantía juvenil, tanto si era demandante de empleo como si no. También con la reforma ejecutada en el 2016 se mantuvo la necesidad de presentar una declaración expresa de tener interés en participar en el Sistema Nacional de Garantía Juvenil, si bien en el caso de los demandantes de empleo bastaba con su inscripción en los servicios públicos de empleo para entenderla realizada.

Las importantes reformas llevadas a cabo respecto de la garantía juvenil en diciembre de 2016, así como también la de 2019 que abrió la franja de edad de lo que se entiende por jóvenes a los efectos de la garantía juvenil, impulsó el número de solicitudes para acceder al sistema, ya que de las 216.334 solicitudes presentadas en enero de 2016 (previas a la reforma legal), se pasó a ese mismo mes pero ya en 2018 a 1.092 .477 y en 2020 a 1.806.882 para acabar superando ya los dos millones en enero de 2021 (2.032.588 para ser exactos). Ese aumento constante puede verse propulsado por los efectos que va dejando la crisis económica y social derivada de la pandemia del coronavirus COVID19; como ha alertado la Comisión Europea en su Comunicación de julio de 2020 "Apoyo al empleo juvenil: un puente hacia el empleo para la próxima generación”, los jóvenes se han visto desproporcionadamente dañados por esta crisis ya que, más de uno de cada seis en el ámbito europeo ha dejado de trabajar desde que se inició.

Ante este panorama, es necesario que el sistema nacional de garantía juvenil propulse su capacidad de atender al colectivo de jóvenes y les dote, en el término de cuatro meses, bien de una acción formativa, bien de un empleo, es más, que aumente la atribución de 
este último tipo de acción, ya que, con datos de 2017, solo el $31 \%$ de las ofertas del sistema de Garantía Juvenil eran ofertas de empleo. Para llevar a cabo ese objetivo es absolutamente necesario partir de la base de que el colectivo de jóvenes no es homogéneo. Si se repara en lo anteriormente dicho sobre los "ninis", entre estos hay desde jóvenes cualificados que en el preciso momento de acceder al sistema no estudian ni trabajan, pero si lo pueden haber hecho anteriormente, hasta jóvenes sin ninguna cualificación educativa o experiencia profesional. Las acciones a dispensar por el sistema en forma de orientación, acciones de educación o formación, fomento de la contratación u ofertas de empleo, deben tener en cuenta esta diferencia para poder llegar óptimamente a cada perfil. Y no solo ella, una función básica de la garantía juvenil es justamente rescatar a los jóvenes que han devenido inactivos, es decir, que no buscan trabajo ni tienen alicientes para acceder al sistema, incluyendo los que lo desconocen, para ello, acciones específicas relativas a servicios sociales de apoyo con un enfoque individualizado por cada caso pueden resultar determinantes para conseguirlo. Finalmente, y relacionado con lo anterior, debe considerarse específicamente la especial vulnerabilidad de las mujeres jóvenes y de los migrantes en el acceso al empleo: justamente, en este último aspecto, debe traerse a colación la autorización llevada a cabo por el Real Decreto-ley 2/2021 de que se permita la inscripción en el sistema de los extranjeros menores de edad no acompañados simplemente a través de la acreditación de los servicios de protección.

Para poder realizar con éxito esta encomienda, es necesario plantear todas las acciones impulsadas por el sistema bajo los planteamientos que se derivan de dos iniciativas políticas de fuerte calado de la Unión Europea que han tenido por objeto estricto el impulso a una Garantía Juvenil Reforzada, por un lado, la Recomendación del Consejo de la Unión Europea de 20 de octubre de 2020, y por otro la Resolución del Parlamento Europeo de 8 de octubre de ese mismo mes.

Según el Consejo de la UE los Estados miembros deben garantizar que todos los jóvenes menores de 30 años reciban una buena oferta de empleo, educación continua, formación de aprendiz o prácticas dentro de un período de cuatro meses tras quedarse desempleado o abandonar la educación formal; debe subrayarse en ese adjetivo que se acompaña a los objetivos a cumplir por cada Estado, en concreto que la oferta de empleo o formación sea "buena", es decir, que sea de calidad. Es más, la Resolución del Parlamento Europeo va algo más allá de la Recomendación del Consejo y advierte que la garantía juvenil debe superar el enfoque de dotar de mayor empleabilidad a los jóvenes, para pasar a concebirse como una vía destinada a garantizar puestos de trabajo permanentes y de calidad para los jóvenes. Dicho de otra manera, la Garantía Juvenil debe dar preferencia a la provisión de empleo a los jóvenes, pero no de cualquier tipo sino solo de aquél que sea de calidad, de carácter estable y con protección social. 
En segundo lugar, como al efecto recomienda el Consejo Europeo, que la inscripción del joven en el sistema debe llevar a que las entidades participantes realicen una serie de acciones bien estructuradas, principalmente el mapeo de los jóvenes a los que se dirigen; la divulgación de sus actividades, especialmente entre los grupos vulnerables; la potenciación de las funciones de asesoramiento, orientación y tutoría; la efectividad de los incentivos para el empleo y para la puesta en marcha de empresas que se adopten; y por último y no menos importante, la dotación debida de sus acciones, empezando por la necesidad de garantizar que los proveedores de la garantía juvenil tengan la capacidad adecuada en cuanto a recursos humanos. Verdaderamente, este último aspecto será clave para evaluar la eficacia que la garantía juvenil reforzada tenga como vía cardinal para potenciar el empleo de los jóvenes.

En definitiva, la batalla es titánica en las actuales circunstancias, pero la necesidad de que la Garantía Juvenil Reforzada tenga éxito es necesario para que los jóvenes sean conscientes de que se respetan plenamente sus derechos fundamentales. Esos derechos solo serán reconocidos en toda su amplitud si la juventud es consciente que se le garantizan un acceso a oportunidades de empleo y de formación a lo largo de la vida de alta calidad. 